\title{
Patient participation in physical medicine and rehabilitation: a concept analysis
}

\begin{abstract}
Patient participation is crucial and has long traditions in physical medicine and rehabilitation. Despite that, there is a lacking coherent definition of patient participation in this context. By following the steps according to Walker and Avant a concept analysis of patient participation in rehabilitation has been conducted. Three attributes to patient participation in rehabilitation emerged: Active patient; Engagement and exchange from both the patient and the rehabilitation professionals; and Focus on the patient's condition, needs, desires and preference. If the attributes are fulfilled; the patient is treated as a capable person and will have greater motivation for being active throughout the rehabilitation. Further consequences of patient participation include improved physical functioning, coping, self-management and satisfaction with care. This study gives a suggestion for a common language in physical medicine and rehabilitation with regard to what patient participation conceptually means.
\end{abstract}

Volume 3 Issue I - 2018

\author{
Jeanette Melin \\ Institute of Health and Care Sciences, Sahlgrenska Academy, \\ University of Gothenburg, Sweden
}

\begin{abstract}
Correspondence: Jeanette Melin, Institute of Health and Care Sciences, Sahlgrenska Academy, University of Gothenburg,
\end{abstract} Sweden, Tel +46105166639, Email Jeanette.melin@ri.se

Received: January 08, 2017| Published: January 24, 2018

Keywords: patient involvement, goal-setting, shared decision-making

\section{Introduction}

Patient participation is essential in physical medicine and rehabilitation. ${ }^{1-4}$ The consensus about the importance of patients actively participating in their rehabilitation is unquestionable in the literature that refers to theories of rehabilitation, behavioral change and learning. ${ }^{5-9}$ In general, rehabilitation is primarily a process of education to improve the patient's physical, sensory, intellectual, psychological and social functioning ${ }^{10}$ to assist the patient in coping with his or her life situation with as little support as possible ${ }^{8}$ and to facilitate the learning process of how to live a life with a disability in one's own environment. ${ }^{9}$ An injury or disease requires a change in the patient's behavior and an adjustment to the new situation. ${ }^{9}$ Since a person acts for a reason, i.e. has a goal-directed behavior ${ }^{11,12}$ a crucial part of the rehabilitation is to implement interventions as meaningful and relevant for the patient. ${ }^{1,13}$

The role of participating patients can be tracked back to 1950s. ${ }^{6,14,15}$ In 1955 Szasz and Hollender ${ }^{15}$ described different basic models of the physician-patient relationship. They related 'mutual participation' to rehabilitation, i.e. the patient's own experiences provide reliable and important clues for therapy and the treatment program itself is principally carried out by the patient. ${ }^{15}$ Hence, the patient should be considered as a person responsible for his or her own acts and behaviors. ${ }^{6}$ and without the patient participating in his or her rehabilitation, therapy can achieve little..$^{1,14}$ In the past 20 years four concept analyses of patient participation have been published. ${ }^{16-19}$ Three of them have their origin in nursing, ${ }^{16-18}$ and one in a general hospital setting. ${ }^{19}$ Surprisingly, despite the long traditions and encouragement of patient participation in rehabilitation ${ }^{1-4,14,15}$ there are no concept analyses focusing on patient participation in a rehabilitation context. It has been showed that a closely related concept, person-centeredness, is used differently due to contexts and professions. ${ }^{20-22}$ Therefore, it is likely that it also true for patient participation and a conceptual analysis is needed. By following the eight steps of content analysis according to Walker \& Avant. ${ }^{23}$ (Table 1) this paper aims to provide clarity in the use of the concept of patient participation in physical medicine and rehabilitation by identifying and defining attributes, antecedents, consequences and empirical referents.

Table I The eight steps for a concept analysis according to Walker ${ }^{23}$

Steps
Select a concept
Determine the aims of the analysis
Identify uses of the concept
Determine defining attributes
Develop a model case
Develop additional cases: borderline and contrary cases
Identify antecedents and consequences
Define empirical referents
General use of the concept patient
Participation

The concept "patient participation" is a two word construct. A "patient" refers to an individual or person receiving therapeutic, diagnostic, preventive or medical treatment in the health care system. ${ }^{24,25}$ Synonyms are "sick person", "case", "suffer", "victim", "invalid", "convalescent", "the sick", "the inform" or "valetudinarian". ${ }^{25}$ "Client" is also a term for patient that can be used interchangeably. ${ }^{24}$ Participation means literally "the action of taking part in something" and involvement, taking part, part, engagement, contribution, sharing, association, partaking and joining in are possible synonyms. ${ }^{25}$ The International Classification of Functioning, Disability and Health (ICF) state that participation "is involvement in a life situation". ${ }^{26}$ The ICF definition of participation refers to a number of activities a person can participate in ${ }^{26}$ though not, related to participation in the role as patient. 
As a Mesh-term, patient participation was introduced in 1978 and defined as "Patient involvement in the decision-making process in matters pertaining to health". ${ }^{24}$ Same definition of patient participation is provided in the Medical Dictionary Online..$^{27}$ The appearance of decision-making is also evident in the Free Dictionary by Farlex definition of patient participation: "A process in which both the patient and physician contribute to the medical decisionmaking process". ${ }^{28}$ Moreover, in the general concept analysis, Castro colleagues (19, p. 1929) define patient participation as "revolves around a patient's right and opportunities to influence and engage in the decision making about his care through a dialogue attuned to his preferences, potential and a combination of his experimental and professional's expert knowledge".In the three previous concepts analysis steaming from nursing there are some commonalities about the attributes of patient participation, such as a relationship between the patient and nurse; a surrendering of power from the nurse to the patient; a sharing information and knowledge building; and an action phase with actively engagement. ${ }^{16-18}$

Patient involvement, patient empowerment, patient activation or patient engagement are alternative entry terms to patient participation in MeSH. ${ }^{24}$ The Free Dictionary by Farlex mean that patient participation can also be called shared decision-making. ${ }^{28}$ In one of the previous concept analyses from nursing, Jo Cahill ${ }^{16}$ states that there is a hierarchical relationship, i.e, patient involvement/ collaboration is a prerequisite for patient participation. ${ }^{16}$ Moreover, with patient empowerment in focus Fumagalli and colleagues ${ }^{29}$ provide an analysis of several of those related terms to patient participation, including patient participation. In their concept mapping, patient participation and patient involvement is placed on the behavioral side whilst patient empowerment, patient activation, patient engagement and patient enablement are placed on the side of process and emergent state. Those sides are reciprocal connected in terms of both exploitation of motivation to increase patient participation and transferring motivation through the patient's participation. ${ }^{29}$ A linear relationship is in contrast to that, Castro and colleagues suggest. ${ }^{19}$ suggest that patient participation is a strategy that will facilitate a patient-centered approach, which in turn leads to patient empowerment. Likewise, Sahlsten and colleagues ${ }^{17}$ identified patient empowerment as a consequence from patient participation. Another contrast is, Thórarinsdóttir \& Kristijánsen ${ }^{18}$ that do not make any differences between patient participation and consider concepts such as partnership, involvement, participation in decision-making and shared decision-making.

\section{Specific use of the concept patient participation}

In physical medicine and rehabilitation a diverse use of patient participation is evident. Some studies refer to patient participation as something objective, e.g. patients attending, being involved or take action in a specific program or intervention. ${ }^{30-37}$ The simplest way of classify participation is dichotomous, attendance compared to non-attendance. ${ }^{30}$ Other studies do, however, provide degrees of patient participation. ${ }^{35-37}$ As suggestions for patient participation in goal-setting include: no participation; a little participation (i.e. asking the patient to give a broad goal for his or her rehabilitation); some participation (i.e. asking the patient to specify areas of activity performance they want to work on); or full participation (i.e. empowering the patients to actively choose goals and set time frames for them to be achieved). ${ }^{35}$ Another way of classifying degrees of patient participation and interaction with rehabilitation professionals (RP) in their rehabilitation planning is free choice level (i.e. the patient can answer four specified questions about his or her goals and goal attainment); multiple choice level (i.e. the RPs provide questions with three possible answers); forced choice level (i.e. the RPs provide a question and offer an answer); or no choice level (i.e. the RPs tells the patient what to do, and the patient may answer yes or no). ${ }^{36}$ From an interview study about patients' perceptions of their participation, three categories have been reported. ${ }^{37}$ These categories are relinquishes (i.e. not interested in participating, easily accepts plans and decision supplied by the RPs); participants (i.e. shared decision-making and team discussions with the RPs); and occasional participants (i.e. restricted to participate due to RPs only occasionally asked for their participation) ${ }^{37}$ Furthermore, other qualitative studies have suggested that the degree of active participation depends on the patient's vitality. ${ }^{38,39}$ A patient may have little strength and energy in the initial phase after an injury. ${ }^{38,39}$ Further possible situations affecting patient participation are patient characteristics, such as being passive and dependent or controlling and independent, leading to different responses to participation. ${ }^{14}$ Some patients adapt a role they believe is a "good patient" characterized by passivity and compliance. ${ }^{40}$ Nevertheless, participation gradually can take place..$^{38,39,41}$ The RPs must increasingly facilitate active participation ${ }^{42}$ and the patient's capacity to plan, decide and control. ${ }^{14}$

Other studies refer to the process of participation and its subjective meaning for the patients. ${ }^{38,39,43-45}$ Some examples are being in an exchange process ${ }^{43}$ a mutually shared process ${ }^{44}$ and becoming in charge as soon as possible, but not until they felt ready. ${ }^{38}$ The patient is present as an actor in all three examples and they all refer to the encounter between the patient and the RPs. With regard to the patients' description of participation the encounter is most fruitful when RPs invite them to a dialogue. ${ }^{43}$ Patients can experience that they participate in the encounter when they can respond to the suggestions made by the RPs and when they are asked for opinions. . $^{43,45,46}$ Moreover, patients feel that they participate when they are respected as unique persons $s^{39,43,45-47}$ and when their opportunities to participate are individually tailored. $5,36,37,39$

In relation to patient participation there are two rehabilitation activities frequently used, namely goal planning and shared decisionmaking. Planning and setting goals is a well-developed and well-used strategy in rehabilitation, wherein the patient's participation is nonarguable. . $^{61,34,39,48-53}$ (The patient should be active in defining his or her needs, what important goals and outcomes are, as well as priority and weight different outcomes. ${ }^{6,50,51}$ However, the patient needs help and coaching in this process. ${ }^{39,52}$ The patient has his or her subjective needs and wishes, while the RPs their clinical expertise. ${ }^{4}$ Goal setting is about negotiation and an agreement between the patient and the RPs is sought. ${ }^{4,11,49,53}$ Setting goals and priorities is a type of shared decision-making that occurs in rehabilitation. ${ }^{54,55}$ Mirjam Körner ${ }^{55}$ refers to shared decision-making as an ideal model for the patient's participation. This should be shaped by communication, cooperation, coordination and (working) climate between the patient and RPs. ${ }^{56} \mathrm{~A}$ frequently used reference for shared decision-making originates in the patient-physician encounter. ${ }^{57}$ Charles and colleagues ${ }^{57}$ suggested that shared decision-making requires at least two participants (i.e. patient and $\mathrm{RP} / \mathrm{s}$ ) who share information, take steps to build a consensus about the preferred treatment and reach an agreement on the treatment to implement. Furthermore, there may be a hierarchy between decision-making and patient participation. Lawrence Schlesinger ${ }^{14}$ 
claims that allowing the patient to participate in decision-making will also make the patient partake more active in the rehabilitation process.

Patient participation is commonly addressed in the modern literature regarding person-centeredness. This is done either by considering patient participation and a person-centered approach as synonyms ${ }^{47}$ or by considering patient participation as a prerequisite for and a vital part of person-centeredness. ${ }^{6,51}$ Specifically, Nordin and colleagues ${ }^{47}$ claim that in practice, patient participation can be described by the Person-Centered Medicine model, i.e. patient participation is about understanding the patient as a whole person, acknowledging the patient's expertise, shared decision-making and developing a patientprofessional relationship..$^{58,59}$ The second, and probably most common way of looking at it, is that patient participation is considered as a vital component of person-centered care. ${ }^{6,51}$ For instance, Leplege and colleagues $^{6}$ identified four conceptual pictures of the use of personcenteredness, one of them was Person-centeredness means that the person as an expert: Participation and empowerment. Another example is Cheryl Cott ${ }^{51}$ who found that Participation in goal setting and decision-making is one of seven components in client-centered rehabilitation.

\section{Attributes to patient participation}

As shown in the previous section there are different uses; therefore, the three attributes of patient participation in rehabilitation are a synthesis of the uses of patient participation in physical medicine and rehabilitation (Figure 1):

i. Active patient. The patient should be the principal character in his or her rehabilitation. An underlying principle is that the patient is a subject legally responsible for his or her actions and wants to be in charge of his or her own rehabilitation. The patient may, although, not prefer or is not capable for an active role initially or in all situations. Hence, the RPs should be observant on the patient's abilities to increasingly facilitate his or her active participation. $6,14,30,35,37,38,43,45,46,50,51,57$

ii. Engagement and exchange from both patient and RPs. In rehabilitation the collaboration and teamwork between the patient and RPs is crucial, e.g. during goal-setting, planning and therapy sessions. Both parts are seen as important contributors; patients with their subjective experiences and RPs with their medical and clinical competence, which they must share. ${ }^{4,11,37,39,43,44,49,51,53,55,57}$

iii. Focus on and respect for the patient's condition, needs, desires and preferences. The individual patient's situation - past, current and future - is the major concern within his or her rehabilitation. The focus is not only limited to the rehabilitation setting, it goes beyond the hospital walls and the patient is viewed as a person who should return to his or her life. It is the patient's rehabilitation; therefore, what is relevant and important for the patient serves as the basis for rehabilitation. ${ }^{5,6,36,39,43,45-47,50,51}$

Figure 1. An illustration of antecedents, facilitators, attributes, consequences and empirical referents to patient participation in physical medicine and rehabilitation. The bullet points in each part are summaries of what has emerged from this concept analysis of patient participation in rehabilitation. The arrows show its relationship to one and another. It is a dashed arrow from facilitators to attributes as this was crucial in the rehabilitation literature, but facilitators are not originally a part of the concept analysis.

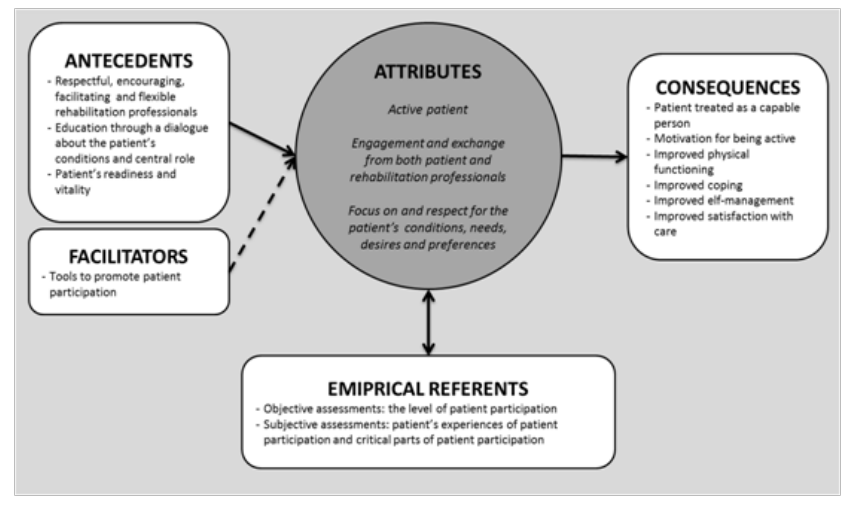

Figure I An illustration of antecedents, facilitators, attributes, consequences and empirical referents to patient participation in physical medicine and rehabilitation.

\section{Model, borderline and contrary cases of patient participation}

As illustrated below, patient participation in physical medicine and rehabilitation assume an active patient where there is an engagement and exchange from both the patient and the RPs and a focus on and respect for the patient's condition, needs, desires and preference. Peter is a patient at a spinal unit. He is suffering from a spinal cord injury after a traffic accident. When negotiating Peter's goals his experiences of his condition, needs, desires and preferences are the main focus. The RPs listen carefully to get to know Peter as a person and understand what the important and relevant aspects in his life are. The medical and clinical knowledge of the RPs is presented to Peter. The goals for the rehabilitation are jointly developed and serve as a basis for Peter's rehabilitation plan. The RPs encourage Peter to be an active participant in his rehabilitation, although, they take it step-by-step to accommodate to his readiness. As the rehabilitation proceeds Peter is taking on more responsibilities and agency in his rehabilitation. Though the process the RPs are sensitive to changes in Peter's condition as well as needs, desires and preferences. Peter's increased activity can happen because of the teamwork, including engagement and exchange from both Peter and the RPs.

A borderline case to patient participation in rehabilitation could be if the patient is active and there is an exchange between the patient and RPs, but what is most relevant for the patient is not addressed, for example. Sara is a patient at an orthopedic ward as she has recently gone through surgery for hip fracture. When the RPs meet Sara and ask for her goals they listen carefully. Sara is explicit in telling her wish to do gardening again. The RPs can present medical limitations that may prevent gardening after the hip fracture. It is followed by the RPs disregard for Sara's wish, rather than by suggested alternatives or potential other ways. The RPs encourage Sara to be active in her training and see her potential in taking own responsibilities. Sara is a compliant patient, tries her best to be active and learn from the RPs. Nevertheless, Sara seeks confirmation and asks for new goals related to her wish to do gardening. They can have a dialogue about it, but once again, it ends up in RPs not respecting and providing help toward achieving Sara's major concern.

In contrast to the attributes to patient participation in rehabilitation above, the patient as an active and capable part is neglected and the patient-RPs encounter consist of one-way communication where the 
RPs stipulates the rehabilitation without considering the patient's wishes. Anna is 80 years old and has had a pulmonary infection. Anna's conditions are now stable and she has been admitted to a geriatric ward. When Anna meets the RPs they go straight forward and tell her about the plan for mobilization and the time of discharge. The RPs do not ask for Anna's opinions, since they know what the best is for Anna. The RPs do not take into account any ideas suggested by Anna though the rehabilitation, they just follow their pre-stipulated plan.

\section{Antecedents and consequences of patient participation}

The RPs as facilitators of patient participation is evident (Figure 1). They must be respectful for and listen to the patient's unique situation and conditions ${ }^{39,43,45,46}$ they must encourage and invite the patient to participate and proceed in his or her rehabilitation ${ }^{37,39,42}$ and they must be flexible and allow individually tailored rehabilitation..$^{5,36,39,47}$ The RPs must also educate the patient about his or her condition ${ }^{39,43,54}$ as well as the rehabilitation process ${ }^{5,44,50,53,60}$ and the patient's role within it. ${ }^{61}$ All patients may, however, not be ready or understand his or her central role..$^{38,39,43}$ and the patient needs to accept and adapt to this role before he or she can take an active part. ${ }^{40,44,61}$

Different tools and working procedures to promote the patient's active role, in particular in setting his or her goals, are commonly used. ${ }^{62}$ Those cannot be classified as antecedent, rather it should be considered as facilitators. Some examples are The Goal Attainment Scale (GAS $)^{63}$ Patient Goal Priority Questionnaire (PGPQ). ${ }^{64}$ The Patient Participation System. ${ }^{36}$ The Canadian Occupational Performance Measure (COPM) ${ }^{65}$ and The Needs Assessment Checklist (NAC). ${ }^{66}$ In practice, such tools can be used to invite and encourage the patient to identify and describe his or her needs, preferences and goals. This can allow both shared discussions between the patient and RPs as well as set the focus on the patients past current and future situation.

Patient participation supports the overall goal with the rehabilitation, i.e. improvement in functions as well as facilitation the patient's everyday life benefit from patient participation. It has been argued that patients actively participating in therapy sessions are more attentive to instructions and receptive to feedback and also work harder. ${ }^{67}$ Hence, they will get more out of their rehabilitation. ${ }^{67}$ Objective assessments of the patient's participation are positively correlated to improved physical functioning. ${ }^{6-74}$ Likewise, interventions to increase the patient's participation are associated with better coping ${ }^{49,75}$ self-management. ${ }^{76-78}$ and satisfaction with care. ${ }^{49,75,79}$ A consequence evident in qualitative studies of patient participation is that the patient is treated as a whole person with dignity. ${ }^{39,43}$ This can be considered in line with the rehabilitative view of the patient as capable and responsible for his or her own acts and behaviors. ${ }^{1,6,14,80}$ Moreover, a patient who takes part in decision making ${ }^{14}$ or goal setting ${ }^{45,80}$ may have a greater motivation for actively participating in the whole rehabilitation process. Those consequences are summarized in Figure 1.

\section{Empirical referents for patient participation}

Both subjective and objective assessments are possible for determining patient participation in physical medicine and rehabilitation (Figure 1). Rettke and colleague ${ }^{81}$ report three different instruments for measuring patient participation in rehabilitation: the Pittsburg Rehabilitation Participation Scale (PRPS); $;^{72}$ the Rehabilitation Therapy Engagement Scale (RTES) ${ }^{82}$ and the Hopkins Rehabilitation Engagement Rating Scale (HRERS).$^{71}$ All these three instruments indicate that patient participation is about the degree of patient participation. Those are measurements of RPs' perceptions carried out by a single item for apprising the individual extent of participation $;{ }^{72}$ by multi-items that assess aspects such as the patient's attitudes, perceptions and expectations ${ }^{82}$ or by multi-items regarding the patient's therapy attendance, attitude toward rehabilitation and participating behavior. ${ }^{71}$

Another type of instrument is a self-assessment questionnaire from the patient's perspective, for instance the Patient Participation in Rehabilitation Questionnaire (PPRQ) ${ }^{83}$ The PPRQ consists of five scales corresponding to central aspects of patient participation; Respect and integrity, Planning and decision-making, Information and knowledge, Motivation and encouragement, and Family involvement. ${ }^{83}$ In contrast to objective assessments, with PPRQ patient participation is a subjective experience. Another self-assessment questionnaire is the Client Centered Rehabilitation Questionnaire (CCRQ) developed by Cott and colleagues. ${ }^{84}$ The CCRQ has one sub-scale for assessment of Patient participation in decision-making and goal-setting (84). Moreover, the CCRQ also has a scale for educational aspects ${ }^{84}$ which can be of importance in relation to the patient's participation.

Furthermore, Körner ${ }^{55}$ suggests that The 9-item Shared DecisionMaking Questionnaire (SDM-Q-9) ${ }^{85}$ can be used for assessment of patient participation in rehabilitation. The SDM-Q-9 is a selfassessment questionnaire for evaluation of the patient's experiences of how shared-decision-making has been facilitated. ${ }^{85}$ Likewise, general assessments of quality of care, such as The Picker Patient Experience Questionnaire (PPEQ) ${ }^{86}$ also includes aspects related to the patients partaking in decisions and provision of information. Moreover, not specifically developed for rehabilitation, but for chronic conditions there are the self-assessment questionnaires The Patient Activation Measure (PAM) $)^{76,77}$ and The Patient Assessment of Chronic Illness Care (PACIC) ${ }^{87}$ The PAM evaluates the patient's knowledge, skills and confidence for self-management. ${ }^{76,77}$ The PAM mainly focuses on the patient's abilities for managing his or her condition, but one item addresses the patient's active role in care and rehabilitation. ${ }^{76,77}$ The PACIC includes five sub-scales, and two of them, Patient activation and Goal-setting, relate to the patient's participation. ${ }^{87}$

\section{Study limitations}

When interpreting the findings, with such an amount of literature written about rehabilitation there is obviously a risk to have overlooked some information that could have contributed to the analysis. This may especially be a problem since sources only written in English could be included. However, to minimize the risk of omitting valuable sources and obtain a picture as clear as possible of the use of patient participation, an attempt has been made to read and include literature from different sources, fields and professions. This analysis did not aim to distinguish patient participation between different professionals. Rather the intention was to provide clarity of what patient participation conceptually means within the wide spectrum of rehabilitation. There may, however, be certain diversifications in the patient-physician, patient-occupational therapist, patient-physiotherapist encounters etc. Furthermore, critique exists of the use of concept analysis it is seen as adapting to a reductionistic and positivistic stance.$^{88}$ However, Walker 
and Avant $^{23}$ claim that concept analysis can increase the richness and clarity of a concept's use, which is important as concepts serve as critically bricks within theories. Moreover, to make use of a concept analysis it must be rigorously linked to the knowledge in a discipline. ${ }^{89}$ In this case, the concept of patient participation in rehabilitation has long traditions and is an obvious part. But as shown in the section about its use, a coherent definition seems to be lacking.

\section{Concluding remarks}

As there seems to be a non-common language this conceptual analysis can give support to what patient participation conceptually means. In order to provide clarity in how the concept of patient participation in physical medicine and rehabilitation is used; it assumes an active patient, engagement and exchange from both the patient and the RPs, and focus on the patient's condition, needs, desires and preferences. The antecedents emerged from this concept analysis underpin the importance of RPs skills to promote actively participating patients. RPs must be empathic and respectful to the patient, provide information about both the patient's condition and the rehabilitation process, as well as allow the patient to participate according to their individual needs and in a flexible manner.

\section{Acknowledgements}

None.

\section{Conflict of interest}

The author declares no conflict of interest.

\section{References}

1. Wade D. Rehabilitation-a new approach. Part two: the underlying theories. Clin Rehabil. 2015;29(12):1145-1154.

2. Wade D. Rehabilitation-a new approach. Overview and part one: the problems. Clin Rehabil. 2015;29(11):1041-1150.

3. Gutenbrunner C, Ward AB, Chamberlain MA, et al. White book on physical and rehabilitation medicine in europe. $J$ Rehabil Med. 2007;39(45):1-48.

4. Gutenbrunner C, Meyer T, Melvin J, et al. Towards a conceptual description of physical and rehabilitation medicine. Journal of Rehabilitation Medicine. 2011;43(9):760-764.

5. Aadal L, Kirkevold M. Integrating situated learning theory and neuropsychological research to facilitate patient participation and learning in traumatic brain injury rehabilitation patients. Brain Injury. 2011;25(7-8):717-728.

6. Leplege A, Gzil F, Cammelli M, et al. Person-centredness: Conceptual and historical perspectives. Disabil Rehabil. 2007;29(20-21):15551565 .

7. Sigert R, Taylor W, Dean SG. Introduction. In: Dean SG, Siegert R, editors. Interprofessional Rehabilitation: A person-centred approach. 1st ed. USA: John Wiley \& Sons; 2012. p. 1-8.

8. Barnes M, Ward A. Concepts of rehabilitation. In: Barnes M \& Ward A, editors. Oxford Handbook of Rehabilitation Medicine. 2nd ed. USA: Oxford University Press; 2009. p. 1-20.

9. Trieschmann RB. Spinal cord injuries. Psychological, Social and Vocational Rehabilitation. 1988.

10. http://www.who.int/topics/rehabilitation/en/
11. Wade DT. Goal setting in rehabilitation: An overview of what, why and how. Clinical Rehabilitation. 2009;23(4):291-295.

12. Levack W, Dean SG. Processes in rehabilitation. In: Dean SG \& Siegert R editors. Interprofessional Rehabilitation: A Person-centered approach. 1st ed. USA: John Wiley, Sons; 2012.

13. Randall KE, McEwen IR. Writing patient-centered functional goals. Phys Ther. 2000;80(12):1197-1203.

14. Schlesinger LE. Staff authority and patient participation in rehabilitation. Rehabilitation literature. 1963;24:247-249.

15. Szasz TS, Hollender MH. A contribution to the philosophy of medicine; the basic models of the doctor-patient relationship. AMA Arch Intern Med. 1956;97(5):585-592.

16. Cahill J. Patient participation: A concept analysis. Journal of Advanced Nursing. 1996;4(3):561-571.

17. Sahlsten MJ, Larsson IE, Sjostrom B, et al. An analysis of the concept of patient participation. Nurs Forum. 2008;43(1):2-11.

18. Thorarinsdottir K, Kristjansson K. Patients' perspectives on personcentred participation in healthcare: a framework analysis. Nurs Ethics. 2014;21(2):129-447.

19. Castro EM, Van Regenmortel T, Vanhaecht $K$, et al. Patient empowerment, patient participation and patient-centeredness in hospital care: A concept analysis based on a literature review. Patient Educ Couns. 2016;99(12):1923-1939.

20. Kitson A, Marshall A, Bassett K, et al. What are the core elements of patient-centred care? A narrative review and synthesis of the literature from health policy, medicine and nursing. J Adv Nurs. 2013;69(1):4-15.

21. Jesus TS, Bright F, Kayes N, et al. Person-centred rehabilitation: What exactly does it mean? Protocol for a scoping review with thematic analysis towards framing the concept and practice of person-centred rehabilitation. BMJ Open. 2016;6(7).

22. Bright FAS, Kayes NM, Worrall L, et al. A conceptual review of engagement in healthcare and rehabilitation. Disabil Rehabil. 2015;37(8):643-654.

23. Walker LO, Avant KC. Strategies for theory construction in nursing. 5th ed. USA: Prentice Hall; 2011. p. 6-243.

24. https://www.ncbi.nlm.nih.gov/mesh/

25. https://en-oxforddictionaries-com.ezproxy.ub.gu.se/

26. International classification of functioning. disability and health. Geneva: World Health Organization,Switzerland; 2008.

27. http://www.online-medical-dictionary.org/definitions-p/patientparticipation.html

28. http://encyclopedia.thefreedictionary.com/patient+participation

29. Fumagalli LP, Radaelli G, Lettieri E, et al. Patient Empowerment and its neighbours: clarifying the boundaries and their mutual relationships. Health policy. 2015;119(3):384-394.

30. Sohanpal R, Steed L, Mars T, et al. Understanding patient participation behaviour in studies of COPD support programmes such as pulmonary rehabilitation and self-management: A qualitative synthesis with application of theory. NPJ Prim Care Respir Med. 2015;25:15054.

31. Dankner R, Geulayov G, Ziv A, et al. The effect of an educational intervention on coronary artery bypass graft surgery patients' participation rate in cardiac rehabilitation programs: A controlled health care trial. BMC Cardiovasc Disord. 2011;11:60. 
32. Holloway TM, Chesssex C, Grace SL, et al. A call for adult congenital heart disease patient participation in cardiac rehabilitation. International Journal of Cardiology. 2011;150(3):345-346.

33. Horn W, Yoels W, Bartolucci A. Factors associated with patients' participation in rehabilitation services: A comparative injury analysis 12 months post-discharge. Disability and Rehabilitation. 2000;22(8):358362 .

34. Schoeb V, Burge E. Perceptions of patients and physiotherapists on patient participation: a narrative synthesis of qualitative studies. Physiother Res Int. 2012;17(2):80-91.

35. Holliday RC, Antoun M, Playford ED. A survey of goal-setting methods used in rehabilitation. Neurorehabil Neural Repair. 2005;19(3):227-231.

36. Nelson CE, Payton OD. A system for involving patients in program planning. Am J Occup Ther. 1991;45(8):753-755.

37. Lund ML, Tamm M, Br nholm IB. Patients' perceptions of their participation in rehabilitation planning and professionals' view of their strategies to encourage it. Occup Ther Int. 2011;8(3):151-67.

38. Angel S, Kirkevold M, Pedersen BD. Rehabilitation after spinal cord injury and the influence of the professional's support (or lack thereof). $J$ Clin Nurs. 2011;20(11-12):1713-1722.

39. Lindberg J, Kreuter M, Taft C, et al. Patient participation in care and rehabilitation from the perspective of patients with spinal cord injury. Spinal Cord. 2013;51(11):834-837.

40. Joseph WN, Elwyn G, Edwards A. Knowledge is not power for patients: a systematic review and thematic synthesis of patient-reported barriers and facilitators to shared decision making. Patient Educ Couns 2014;94(3):291-309.

41. Ozer MN, Kroll T. Patient-centered rehabilitation: Problems and opportunities. Critical Reviews in Physical and Rehabilitation Medicine. 2002;14(3-4):273-289.

42. Papadimitriou C, Carpenter C. Client-centered practice in spinal cord injury rehabilitation. CARF. 2013;1-42.

43. Nordin C, Gard G, Fjellman WA. Being in an exchange proces: Experiences of patient participation in multimodal pain rehabilitation. Journal of Rehabilitation Medicine. 2013;45(6):580-586.

44. Lexell EM, Lexell J, Larsson LM. The rehabilitation plan can support clients active engagement and facilitate the process of change-experiences from people with late effects of polio participating in a rehabilitation programme. Disability and Rehabilitation. 2016;38(4):329-336.

45. Melander Wikman A, Fältholm Y. Patient empowerment in rehabilitation: Somebody told me to get rehabilitated. . Physiotherapy. 2006;8(1):2332.

46. Slade SC, Molloy E, Keating JL. Listen to me, tell me: A qualitative study of partnership in care for people with non-specific chronic low back pain. Clinical Rehabilitation. 2009;23(3):270-280.

47. Nordin C, Michaelson P, Eriksson MK, et al. It's about me: patients' experiences of patient participation in the web behavior change program for activity in combination with multimodal pain rehabilitation. $J$ Med Internet Res. 2017;19(1):e22.

48. Baker SM, Marshak HH, Rice GT, et al. Patient participation in physical therapy goal setting. Physical Therapy. 2001;81(5):1118-1126.

49. Byrnes M, Beilby J, Ray P, et al. Patient-focused goal planning process and outcome after spinal cord injury rehabilitation: quantitative and qualitative audit. Clinical Rehabilitation. 2012;26(12):1141-1149.

50. Young CA, Manmathan GP, Ward JC. Perceptions of goal setting in a neurological rehabilitation unit: a qualitative study of patients, carers and staff. J Rehabil Med. 2008;40(3):190-194.
51. Cott CA. Client-centred rehabilitation: client perspectives. Disabil Rehabil. 2004;26(24):1411-1422.

52. Gardner T, Refshauge K, McAuley J, et al. Patient led goal setting in chronic low back pain-What goals are important to the patient and are they aligned to what we measure? Patient Education and Counseling. 2015;98(8):1035-1038.

53. Siegert RJ, Taylor WJ. Theoretical aspects of goal-setting and motivation in rehabilitation. Disabil Rehabil. 2004;26(1):1-8.

54. Rose A, Rosewilliam S, Soundy A. Shared decision making within goal setting in rehabilitation settings: A systematic review. Patient Education and Counseling. 2017;100(1):65-75.

55. Körner M. Patient-centered care through internal and external participation in medical rehabilitation Health. 2013;5(6A2):48-55.

56. Korner M, Wirtz MA. Development and psychometric properties of a scale for measuring internal participation from a patient and health care professional perspective. Bmc Health Serv Res. 2013. 3 p.

57. Charles C, Gafni A, Whelan T. Shared decision-making in the medical encounter: What does it mean? (Or it takes, at least two to tango). Social Science and Medicine. 1997;44(5):681-692.

58. Mead N, Bower P. Patient-centredness: A conceptual framework and review of the empirical literature. Soc Sci Med. 2000;51(7):1087-1110.

59. Stewart M, Brown JB, Weston W. Patient-centered medicine. Transforming the Clinical Method. Int J Integr Care. 2003;5.

60. Maitra KK, Erway F. Perception of client-centered practice in occupational therapists and their clients. Am J Occup Ther. 2006;60(3):298-310.

61. Sugavanam T, Mead G, Bulley C, et al. The effects and experiences of goal setting in stroke rehabilitation - a systematic review. Disabil Rehabil. 2013;35(3):177-190.

62. Kamioka Y, Yoshino T, Sugaya K, et al. Goal-Setting Method and Goal Attainment Measures in Physical Therapy for Stroke Patients: a Systematic Review. J Phys Ther Sci. 2009;21(4):399-415.

63. Turner SL. Goal attainment scaling (GAS) in rehabilitation: a practical guide. Clin Rehabil. 2009;23(4):362-370.

64. Åsenlöf P, Denison E, Lindberg P. Behavioral goal assessment in patients with persistent musculoskeletal pain. Physiotherapy Theory and Practice. 2004;20(4):243-254.

65. Law M, Baptiste S, McColl M, et al. The canadian occupational performance measure: An outcome measure for occupational therapy. Can J Occup Ther. 1990;57(2):82-87.

66. Kennedy P, Hamilton LR. The needs assessment checklist: a clinical approach to measuring outcome. Spinal Cord. 1999;37(2):136-139.

67. Teeter L, Gassaway J, Taylor S, et al. Relationship of physical therapy inpatient rehabilitation interventions and patient characteristics to outcomes following spinal cord injury: The SCIRehab project. $J$ Spinal Cord Med. 2012;35(6):503-526.

68. Ozelie R, Gassaway J, Buchman E, et al. Relationship of occupational therapy inpatient rehabilitation interventions and patient characteristics to outcomes following spinal cord injury: The SCIRehab Project. Journal of Spinal Cord Medicine. 2012;35(6):527-546.

69. Bergholdt SH, Sondergaard J, Larsen PV, et al. A randomised controlled trial to improve general practitioners' services in cancer rehabilitation: Effects on general practitioners' proactivity and on patients' participation in rehabilitation activities. Acta Oncologica. 2013;52(2):400-409.

70. Dijkers MP, Faotto RM. Team size in spinal cord injury inpatient rehabilitation and patient participation in therapy sessions: The SCIRehab Project. J Spinal Cord Med. 2012;35(6):624-634. 
71. Kortte KB, Falk LD, Castillo RC, et al. The hopkins rehabilitation engagement rating scale: Development and psychometric properties. Arch Phys Med Rehabil. 2007;88(7):877-884.

72. Lenze EJ, Munin MC, Quear T, et al. The pittsburgh rehabilitation participation scale: Reliability and validity of a clinician-rated measure of participation in acute rehabilitation. Arch Phys Med Rehabil. 2004;85(3):380-384.

73. Morghen S, Morandi A, Guccione AA, et al. The association between patient participation and functional gain following inpatient rehabilitation. Aging Clinical and Experimental Research. 2016;29(4):1-8.

74. Talkowski JB, Lenze EJ, Munin MC, et al. Patient participation and physical activity during rehabilitation and future functional outcomes in patients after hip fracture. Arch Phys Med Rehabil. 2009;90(4):618-622.

75. Bieber C, Mueller KG, Blumenstiel K, et al. Long-term effects of a shared decision-making intervention on physician-patient interaction and outcome in fibromyalgia - A qualitative and quantitative 1 year follow-up of a randomized controlled trial. Patient Educ Couns. 2006;63(3):357366 .

76. Hibbard JH, Stockard J, Mahoney ER, et al. Development of the patient activation measure (PAM): Conceptualizing and measuring activation in patients and consumers. Health Serv Res. 2004;39(4 Pt 1):1005-1026.

77. Hibbard JH, Mahoney ER, Stockard J, et al. Development and testing of a short form of the patient activation measure. Health Serv Res. 2005;40(6 Pt 1):1918-1930.

78. Schmittdiel J, Mosen DM, Glasgow RE, et al. Patient assessment of chronic illness care (PACIC) and improved patient-centered outcomes for chronic conditions. J Gen Intern Med. 2008;23(1):77-80.

79. Holliday RC, Cano S, Freeman JA, et al. Should patients participate in clinical decision making? An optimised balance block design controlled study of goal setting in a rehabilitation unit. $J$ Neurol Neurosur Ps. 2007;78(6):576-580.
80. Pollock N. Client-centered assessment. The American journal of occupational therapy: official publication of the American Occupational Therapy Association. 1993;47(4):298-301.

81. Rettke H, Geschwindner HM. Assessment of patient participation in physical rehabilitation activities: An integrative review. Rehabil Nurs. 2015;40(4):209-223.

82. Lequerica AH, Rapport LJ, Whitman RD, et al. Psychometric properties of the rehabilitation therapy engagement scale when used among individuals with acquired brain injury. Rehabil Psychol. 2006;51(4):331337.

83. Lindberg J, Kreuter M, Person LO, et al. Patient participation in rehabilitation questionnaire (PPRQ) - development and psychometric evaluation. Spinal Cord. 2013;51(11):838-842.

84. Cott CA, Teare G, McGilton KS, et al. Reliability and construct validity of the client-centred rehabilitation questionnaire. Disabil Rehabil. 2006;28(22):1387-1397.

85. Kriston L, Scholl I, Hölzel L, et al. The 9-item shared decision making questionnaire (SDM-Q-9). Development and psychometric properties in a primary care sample. Patient Educ Couns. 2010;80(1):94-99.

86. Jenkinson C, Coulter A, Bruster S. The picker patient experience questionnaire: Development and validation using data from in-patient surveys in five countries. Int J Qual Health Care. 2002;14(5):353-358.

87. Glasgow RE, Wagner EH, Schaefer J, et al. Development and validation of the patient assessment of chronic illness care (PACIC). Med Care. 2005;43(5):436-444.

88. Beckwith S, Dickinson A, Kendall S. The "con" of concept analysis. A discussion paper which explores and critiques the ontological focus, reliability and antecedents of concept analysis frameworks. International Journal of Nursing Studies. 2008;45(12):1831-1841.

89. Cronin P, Ryan F, Coughlan M. Concept analysis in healthcare research. International Journal of Therapy and Rehabilitation. 2010;17(2):62-68. 